Sādhanā Vol. 39, Part 3, June 2014, pp. 625-635. (C) Indian Academy of Sciences

\title{
Parametric and mechanical characterization of linear low density polyethylene (LLDPE) using rotational moulding technology
}

\author{
P L RAMKUMAR*, D M KULKARNI and V V CHAUDHARI \\ Department of Mechanical Engineering, Birla Institute of Science \\ Pilani-Goa Campus, Zuari Nagar, Goa 403 726, India \\ e-mail: ramkumarpl@goa.bits-pilani.ac.in
}

MS received 5 November 2012; revised 21 May 2013; accepted 25 May 2013

\begin{abstract}
In this research work, extensive literature review of the rotational moulding process using linear low density polythene (LLDPE) has been carried out to summarize the present status of the characterization in order to maintain quality and reliability of the products. The present characterization of rotomoulded products using LLDPE is based on the mechanical properties which are being altered by changing process parameters. However, it is observed that in the majority of applications of the products made of LLDPE using rotational moulding technology are prone to cracking failure due to manufacturing defects at room temperature. Therefore, study of fracture characterization of the material is equally important in relation to quality and reliability. In this article, the present characterization of the rotational moulded products using different polymers is summarized in the form of review and the importance of evaluation of the fracture behaviour of rotomoulded products is emphasized.
\end{abstract}

Keywords. Rotational moulding; LLDPE; process parameters; mechanical properties; fracture characteristics.

\section{Introduction}

Rotational moulding process is a thermoplastic processing method for producing hollow parts ranging from simple to complex geometries. Polyethylene and polypropylene are thermoplastics that are part of same polyefine family, out of which more than $80 \%$ polyethylenes are preferred for rotational moulding. Among the different polyethylenes, linear low density polyethylene (LLDPE) is used because of its unique melt flow properties and less shear sensitivity. The present characterization of rotomoulded products is based on mechanical properties. Few investigations have also been done on effect of process parameters, additives and filler material on mechanical properties. However, it is observed that in the majority of the products made by LLDPE using rotational moulding technology fail due to the presence of sharp flaws. Rotational moulding

*For correspondence 
products are used in outdoor applications, e.g., boat, oil /water tanks, and car body parts, etc. In such applications, presence of sharp flaws due to manufacturing defects lead to failure of the products especially at room temperatures. Therefore, there is a need to study the fracture behaviour, which in turn depends on the process parameters.

Even though a lot of manufacturing processes are available to produce hollow plastic parts like injection moulding, thermoforming, blow moulding, etc., currently rotational moulding is a very competitive alternative to all of those moulding processes. Rotational moulding (also called as rotomoulding or rotational casting) is a thermoplastic processing method for producing hollow parts, ranging from most simple to complex geometries. Although rotational moulding has been available as a processing method of plastics for about 45 years, it is only in the last decade the substantial developments have been taking place to put the process on a competitive ground with injection and blow moulding processes. The products obtained from rotational moulding find wide applications in various fields like agriculture, storage tanks, industrial equipments, medical devices, material handling, road/highways, automobiles, etc.

The advantages of rotational moulding process are: (i) The parts produced by rotational moluding process are relatively stress-free compared to other moulding process like injection moulding or blow moulding, since in rotational moulding the plastic is not forced to take up a shape that is not natural for it. (ii) With proper design, parts assembled from several pieces can be moulded as one single part (with no weld lines or joints), eliminating high fabrication costs. (iii) Very large parts can be produced economically using this process.

The quality of a product obtained by rotational moulding process is governed by several process parameters like mould material, rotational speed of mould, oven temperature, cycle time, cooling time, powder size, pigments, etc. The above mentioned process parameters play an important role in deciding the superior mechanical properties as observed by Crawford (1996).

Different thermoplastic powders are being used for rotational moulding like low density polyethylene (LDPE), LLDPE, Metallocene catalysed linear low-density polyethylene (m-LLDPE), cross linked polyethylene (X-LPE), polypropylene (PP), acrylonitrile-butadienestyrene (ABS), nylon (PA11), polyvinyl chloride (PVC), etc. Out of these polymers, LLDPE is preferred for rotational moulding process. LLDPE is a linear polymer (polyethylene), with significant numbers of short branches, commonly made by copolymerization of ethylene with long chain olefins. LLDPE has unique melt flow properties which makes it suitable for rotational moulding process. Another important property which fits this to the process is its less shear sensitivity. The lower shear sensitivity of LLDPE allows for a faster stress relaxation of the polymer chains. The rheological properties of LLDPE are summarized as 'stiff in shear' and 'soft in extension'. Few critical applications of rotomoulding process using LLDPE (along with other materials and additives) material are automobile fuel tanks, oil tanks, chemical tanks, traffic barriers, boats and material handling trolleys. These applications demand superior mechanical properties like impact strength, tensile strength, viscosity, flexural strength and density.

Figures $1(\mathrm{a}-\mathrm{d})$ show four different stages in a rotational moulding process. Figure 1a shows the charging of the mould with polymer powder typically linear low density polyethylene (LLDPE) of melt flow index 4.5-5.5. After charging, biaxial rotation (rotator speed ratio is typically 4:1) in a convective heated environment as shown in figure $1 \mathrm{~b}$ is achieved by supplying heat externally. Cooling with mold rotation (figure 1c) is done where the melted polymer powder gets settled to the walls of the mould. Finally, demoulding (figure 1d) is done to get the product.

The temperature of the polymer inside the rotating mould is critical, as the proper sintering of the polymer is necessary to get a product with uniform mechanical properties. Since monitoring of such temperature is difficult, the internal air temperature of mould is taken as a measure of polymer sintering. The variation of mould internal air temperature during the rotational moulding 


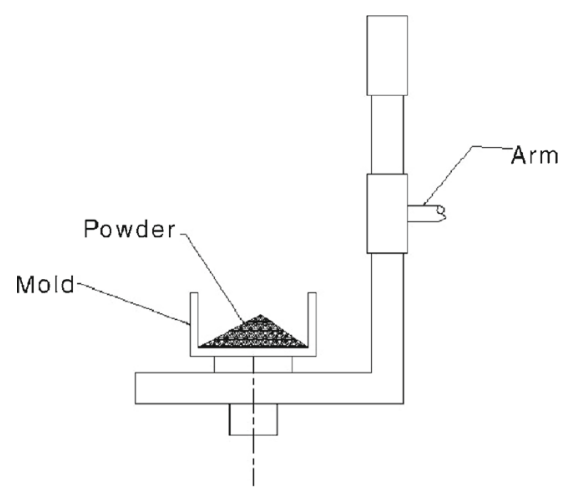

(a)

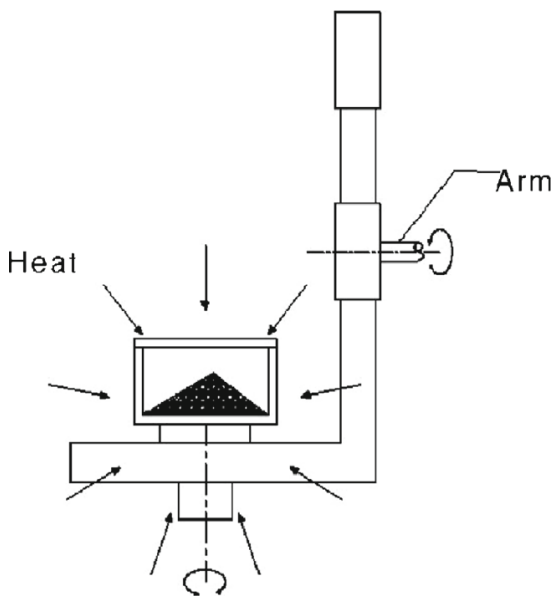

(b)

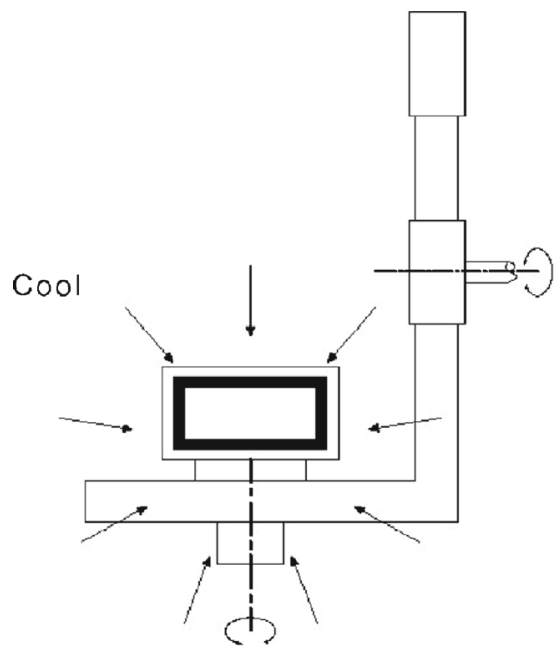

(c)

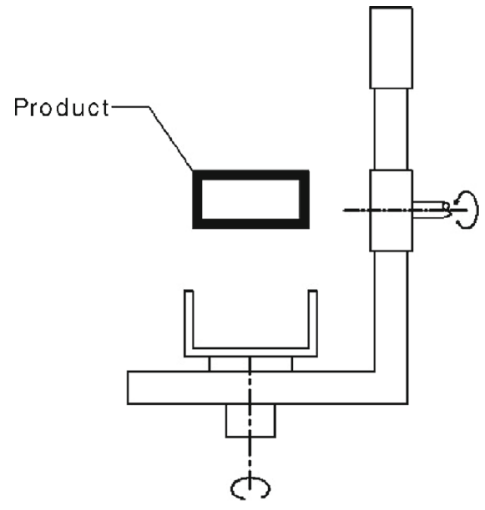

(d)

Figure 1. (a) Mould charging. (b) Mould rotation and heating. (c) Mould rotation and cooling. (d) De moulding.

process using LLDPE as a processing material has been depicted by Crawford (1994) as shown in figure 2.

Heating $(\mathrm{AB})$ is the first stage where heat penetrates into the mould, and the internal air temperature starts to increase at a steady rate. The powder particle tumbles inside the mould without striking the mould. Melting (BC) phase, the temperature reaches to $120^{\circ} \mathrm{C}$ and LLDPE powder starts melting. Once the plastic powder melts, it absorbs a large amount of heat and forms a thin film of melt on the inside surface of the mould. In curing (CD) phase, the individual particles stick together to the surface of the mould and form a loose porous mass. As the temperature increases the powder takes the shape of the mould. The curing temperature for LLDPE is around 


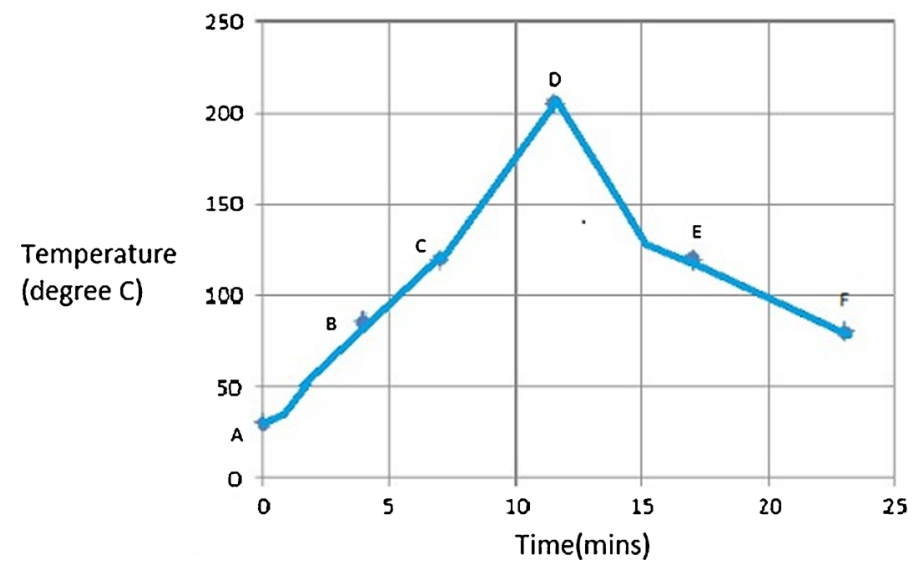

Figure 2. Typical internal air temperature profile of rotational moulding process.

$200^{\circ} \mathrm{C}$. Even though the temperature at the inner surface of mould is lesser than the temperature near to the surface of metal mould the rotational moulded products begin to degrade at the inner free surface. The presence of oxygen at the inner surface initiates the degradation process. Because of the degradation process, crack initiates at the inner surface and propagates rapidly through the rest of the unaffected structure of the plastic as proposed by Crawford (1994). In Cooling (DE) phase, the plastic gets solidified as the temperature decreases inside the mould. The air temperature inside the mould gets reduced due to the release of thermal energy during cooling. The cooling rate is less critical to the properties of mould. In demoulding (EF) phase, the plastic part is allowed to take out from the mould as the mould temperature reaches around $70^{\circ} \mathrm{C}$ at $\mathrm{F}$.

\section{Literature review}

In order to understand the status of the present characterization of LLDPE products using rotational moulding process, the literature review is framed in 3 groups: (i) Process parameters in rotational moulding; (ii) Influence of process parameters on the mechanical properties of LLDPE material using rotational moulding; (iii) Literature on fracture behaviour of polymer.

\subsection{Process parameters in rotational moulding}

The rotational moulding process has been extensively reviewed by many researchers. The importance of study of process parameters in descending orders according to Crawford (1996). Those are: moulddesign and construction to achieve faster cooling, improved methods to predict shrinkage, methods to reduce cycle times, new mould materials, recycling, stress analysis and internal mould release agents. It is highlighted that moulders use a rule of thumb to decide the various processing parameters and have to depend heavily on trial and error methods as well as experience of the operators. Number of process parameters like powder size, shape and distribution, melt flow index (MFI), mould surface, temperature, additives, temperature inside the mould, surface tension, vacuum and pressure, etc. in rotational moulding process play an important role in the formation and/or removal of surface pinholes and internal bubbles in the rotomoulded product. Spence \& Crawford (1996) have shown that a low viscosity material (MFI $25 \mathrm{~g} / 10 \mathrm{~min}$ ) 
produces products in which bubbles or surface pores were not observed. Also overheating can reduce the bubbles, but it may tend to have an adverse effect on the mechanical strength of the product as they are greatly reduced because of thermal degradation as well as overheating results in longer cycle times reducing the efficiency of the process. As per Crawford (2003), different varieties of polymers that can be used in rotational moulding process were decided by some specific characteristics of the polymers which are in terms of conductivity, paintability, processability, etc. This helps in precise control over the process and reduced cycle time. Polypropylene is rotomoulded under a variety of processing conditions. It is observed by Van Hooijdonk et al (2001) that the impact property of polypropylene is significantly influenced by difference in heating and cooling rate. Also, there is very little difference in flexural modulus of samples made using various processing methods. The highest result is achieved for the larger burner conventional machine (1013 MPa), followed by injection moulded samples (941 MPa). There is a 10\% difference between the flexural modulus of the injection moulded samples and samples made of small burner machine. Recently Tan et al (2011) has reviewed the different methods of internal cooling of mould to reduce the cycle times in rotational moulding. The methods of cooling studied by the author include introduction of compressed air inside the mould, introduction of $\mathrm{CO}_{2}$ at cryogenic conditions and water spray cooling. According to authors, the water cooling could be an effective alternative to reduce the cycle times, better structural uniformity of the plastic and hence better mechanical properties.

Hollow glass/ceramic micro spheres with two layers are incorporated into polyethylene to form a multi-layered sandwich construction by rotational molding and syntactic foams are formed. These are found to be light in weight, dimensionally stable, composite materials. It is also reported by Mark Kearns \& Neil Collan (2000) that the use of two-layer moulding gives significant improvements in flexural modulus and considerable reduction in shrinkage of mouldings. However, no benefit has been gained in terms of tensile strength and impact properties of composite mouldings. According to Bharat Indu Chaudhary et al (2001) the weight percentages of the low molecular additives like mineral oil, glycerol monostearate are added to polyethylene as sintering enhancers which results in decreased melt viscosity and elasticity at low shear rate. In uniaxial rotational moulding, due to the addition of sintering enhancer part thickness obtained is uniform and the cycle time is reduced without adversely affecting the impact strength and the same cause is also observed in biaxial rotational moulding.

In the rotomoulding process, the temperature must be sufficiently high to achieve the correct viscous and elastic rheological characteristics in the polymer to promote the coalescence of granular particles, and for removal of trapped bubbles. The processibility relationship for rotational moulding process between the initial powder temperature $\left(\mathrm{T}_{1}\right)$ and polymer degradation temperature $\left(\mathrm{T}_{\mathrm{d}}\right)$ are reported by Abbas Tcharkhtchi \& Jacques Verdu (2004). In general, the polymer is processible if $T_{d}>T_{1}$. According to the authors, in the rotational moulding process the polymer remains in the liquid state for a longer time than the other processes. A comparative study of the Polyethylene with other polymers like aliphatic polyamides, polyethylene terephthalate (PET) or polyvinyl chloride (PVC) shows that the value of $\mathrm{T}_{1}$ for polyethylene is less than all other polymers and degradation starts at $300^{\circ} \mathrm{C}$, which is an optimized temperature for processing of polyethylene in rotomoulding process. Therefore, thermal stability is high in atmospheric temperature. Hence, polyethylene is widely used in rotomoulding industry.

It has been estimated that one third of the failures of moulded plastic parts arises due to residual stress that is developed during the moulding process. However, the major advantage in rotational moulding process is that the residual stress is relatively less compared to other moulding methods. The best approach which is proposed by Crawford (2000) to reduce the residual stress in rotational moulding process is faster internal cooling and exercising the control 
over the release point. Late release from the mould causes lower level of residual stress. Also the use of pressure inside the mould is the best way to control the release point.

Among all the process parameters that are discussed above, cooling and heating rate are the two parameters which play an important role in deciding the mechanical properties of the rotomoulded product. Slow cooling may result in lower impact strength and increased cycle time. Even improper heating or cooling may lead to thermal stress cracking. Along with the above two parameters, the viscosity, additives and foaming agent also affect the property and quality of the material.

\subsection{Influence of process parameters on mechanical properties of LLDPE using rotational moulding}

The roto moulded product quality is greatly influenced by its process variables which in turn, influence mechanical properties of the rotational moulded products. Depending on the criticality of the application the desired mechanical properties of the rotational moulded products are impact strength, tensile strength, viscosity, flexural strength and density. Antonio Greco \& Alfonso Maffezzoli (2004) carried out Powder analysis of recycled high-density polyethylene (RHDPE). Different shape factors capable of characterizing powders are obtained at three different temperatures $\left(\mathrm{T}<40^{\circ} \mathrm{C} ; 60^{\circ} \mathrm{C}<\mathrm{T}<70^{\circ} \mathrm{C} ; 90^{\circ} \mathrm{C}<\mathrm{T}<100^{\circ} \mathrm{C}\right.$ ). It is found that at low temperatures, the viscosity of material being too high, particles obtained at room temperature have a rough surface and irregular shape. At higher temperatures, isotropic configuration of polymer chains is obtained. This allowed cleaner cuts and smoother surfaces. A further increase in temperature leads to premature melting and adhesion of powders and consequently the formation of clusters that are not desirable for rotational moulding. The influence of shape and size of powder particle is studied by thermo-mechanical analysis. The mathematical model followed by experimental investigations confirmed that there exists an optimum sintering temperature at which the density of the sintered product is higher and a good quality rotationally molded product can be fabricated. The nature of powder flow and its effect on the melt deposition of powder materials in rotationally moulded parts is examined. Especially the particle size and shape geometry of LLDPE are studied by Antonio Greco \& Alfonso Maffezzoli (2004). Five different shaped particles of rotational moulding grade polyethylene were tested for its mechanical property. It is found by Throne \& Sohn (1989) that the polyethylene samples have greater strengths and moduli with lesser impact strengths. It also reveals higher crystallinity and larger spherulite dimensions. An experimental set-up developed by Olinek et al (2005) allows analysis particle deposition pattern in rotomoulding process especially to address the problems of thickness distribution, fabricating composites and multi-layered products. Thermomechanical analysis of three powders viz. polyethylene, polypropylene and polycarbonate are conducted. It is found by McNally et al (2002) that for polyethylene the progressive increase in the temperature over a range of 130 to $150^{\circ} \mathrm{C}$, there is a substantial increase in melt density. A further increase in temperature from 150 to $200^{\circ} \mathrm{C}$ resulted in decreasing density indicating melt expansion. However, with further increase in temperature no density change is recorded. At this stage, since the viscosity of the material is lower, it resulted in collapse of bubbles and further densification. Similar trends are observed for the other two specimens polypropylene and polycarbonate. It is found by Spence \& Crawford (1996) that the increased number of fine particles produces more bubbles and reduces the impact strength. They have also shown that the viscosity of melt has significant influence on the flow of powder inside the mould which in turn will affect uniformity in thickness. The relation between the dry flow time and bulk density of rotomoulding resin powders are experimentally studied by Laws (2004). It is found that dry flow 
time increases with increasing material temperature. The property of rotational moulded and injection moulded polypropylene parts is compared by Van Hooijdonk et al (2001). It is found that the impact property of injection moulded sample showed improved crystallinity and impact strength. An experimental investigation done by Oliveria \& Cramez (2001) on morphological development during rotational moulding of polyethylene and polypropylene when mixed with nucleating pigments or different amount of oxidants revealed that the morphology is affected by the processing temperature. Author also observed that the suppression of crystallization occurs during the degradation of polyethylene whereas change in the appearance and the level of birefringence of spherulites occurs during the degradation of polypropylene. An experimental study to establish the relationship between the impact performances of rotationally moulded polyethylene over a range of temperatures from -60 to $20^{\circ} \mathrm{C}$ is reported by Pick \& Harkin-Jones (2003a). Three samples of conventional LLDPE and metallocene catalysed LLDPE is tested for every $10^{\circ} \mathrm{C}$ rise in temperatures between -60 and $20^{\circ} \mathrm{C}$. The result showed that the metallocene catalysed LLDPE has better impact properties than conventional LLDPE. The results also indicated that although high-density polymers show higher impact resistance, the other factor like crystalline morphology plays an important role than density in the impact performance. Further, the work was extended by Pick \& Harkin-Jones (2003b) to find a quantitative relationship between the impact performance and thermal transition of rotomoulded linear low-density polyethylene.

In real time application, the impact performance of the plastic is very important. Pick et al (2003) observed that at a particular test temperature $\left(-60\right.$ to $\left.20^{\circ} \mathrm{C}\right)$ the impact resistance of metallocene polyethylene is higher typically about 1 to $4 \mathrm{~J} / \mathrm{mm}$ than the LLDPE material. The impact strength of LLDPE was compared by Shih-Jung Liu (2000) for five different process variables, four levels of oven temperatures, four different oven times, four different mould materials and four different particle sizes of polyethylene powder. The experimental result showed that the impact strength of the part made of different mould material was: aluminum $>$ brass $>$ mild steel $>$ stainless steel. Experimental design based on Taguchi method are used to prove that the oven temperature and oven time was the principal factors affecting the impact properties of rotationally moulded thermoplastics. According to Guobin et al (2004) in order to improve the mechanical properties like impact strength and tensile strength of hollow cavity made by the rotomoulded products, the product has to be filled with the polyethylene foam materials. It was also proved by Yan et al (2003) that the addition of glass micro spheres with linear medium density polyethylene in the rotational moulding process reduced the cycle time and tensile strength but increased the impact strength. An investigation of the effect of talc and mica on the properties of rotational moulded LLDPE infers that the introduction of finer grades of talc and mica improves the impact strength. It is also found by Robert et al (2000) that when moulding LLDPE $+10 \%$ MICA-MU85 + 3\%PB3009, a reduction of nearly $15 \%$ of overall cycle time is achieved and for the same composition the shrinkage was reduced up to $56 \%$.

Foaming behaviour of metallocene catalysed polyethylene for rotational moulding was examined experimentally. The experimental findings of Archer et al (2002) revealed that metallocene based polyethylene produced foam with lower density than conventional polyethylene and showed a lower flexural property. The rotomouldability of LLDPE foams was examined by ShihJung Liu \& Chja-Hsun Tsai (1999) adding citric acid based blowing agents. The presence of blowing agent increased the impact strength of the product whereas the tensile strength is found to be decreased with increase in blowing agent content. The warpage of the part was also found less with the increase in foaming agent. Nano scale calcium carbonates were used to improve the impact strength of rotationally moulded nano composites with polypropylene as a matrix material. It is found by Alongkorn Kanokboriboon \& Harkin-Jones (2005) that calcium carbonate can be an effective impact modifier for rotomoulded polypropylene with small decrease in 
strength and strain to break. Many polymers used in rotomoulded parts (such as outdoor storage tanks) contain photostabiliser additives. However, it was observed by Mark Kearns et al (2001) that this resulted in a marginal decrease of some mechanical properties like impact strength.

Among all the mechanical properties, the impact properties of the final product are of great importance. Since many products made by rotational moulding are used in outdoor applications, e.g., boats, tanks, and car body parts. In such applications, impact loading is very common and quite often the products will be used at low temperatures.

\subsection{Literature on fracture behaviour of polymer}

Generally, polyethylene is a tough, semi-crystalline thermoplastic that has found increasing use in several key engineering applications, such as a pipeline material for water and gas transportation, blow moulded containers for fuel tanks, large solvent drums. However, recently in more demanding applications where resistance to impact is of critical importance, e.g., light weight body armor and riot shields for military and law enforcement personnel. Since the components fabricated from polyethylene are more often prone to failure under impact loading and this tendency of failure is promoted by the presence of sharp flaws, especially at room temperatures. Therefore, fracture behaviour of a polymer is one of the important characteristics required to be evaluated. Fracture of polymer materials can be brittle or ductile or mixture of two. Thermoplastics may fracture primarily by brittle or ductile manner. The fracture mode is considered to be brittle if the fracture of the thermoplastic takes place below its glass transition temperature else it is considered as ductile fracture, whereas the thermosetting plastics are considered to fracture primarily in brittle mode. Fracture toughness generally depends on temperature, environment, loading rate, the composition of the material and its microstructure, together with geometric effects.

Essential work of fracture under tensile and impact loading is used to evaluate the fracture toughness of high density polyethylene-organ clay with montmorillonite (HDPE/org-MMT) nano-composites with/without elastomers. It is found by Tjong \& Bao (2007) that the model cannot be used to describe the fracture behaviour of pure HDPE and its nano-composites at room temperature and necking and cross yielding of the composites takes place at $70^{\circ} \mathrm{C}$. The dynamic fracture behaviour of linear medium density polyethylene under impact loading conditions are assessed by three point bend impact experiment with modified split Hopkinson pressure bar (MHPB). It was found by Carla et al (2007) that the time duration of the stable crack blunting and growth for $6 \mathrm{~m} / \mathrm{s}$ of impact velocity is much shorter than those obtained for lower impact velocities (i.e., $5.4 \mathrm{~m} / \mathrm{s}$ and $2.7 \mathrm{~m} / \mathrm{s}$ ). It was also observed that as impact velocity is increased the time required for dynamic fracture initiation, length of stable crack growth and dynamic energy release rate get decreased. According to Francis et al (1988) morphological analysis of the extraordinary fracture toughness of LLDPE resins compared to low density polyethylene and high density polyethylene resins proved the presence of second soft phase with a weak solvent in a hard semi crystalline matrix results in extraordinary fracture toughness in LLDPE. Essential work of fracture (EWF) concept is used by Tamas Barany et al (2003) to find the plane stress fracture toughness of amorphous co-polyester (COP) sheets of different composition and molecular mass. It is observed that amorphous COPs are ideal polymer for EMF tests, since they undergo full yielding prior to the onset of crack growth. EWF approaches are used to assess the effect of strain rate on the plane stress fracture toughness of various ductile polymeric films (LLDPE-CO-BUT, PA6, and PET). It was found by Alesseandro Pegoretti et al (2005) that specific essential work of fracture component related to crack initiation is increasing with strain rate and where as the crack propagation is decreasing with strain rate. For the prediction of crack 
width and crack spacing in fibre reinforced polymer (FRP) concrete beams an analytical procedure based on the slip and bond stresses is adopted. It is predicted by Aiello \& Ombres (2000) that increase in bond strength of FRP bars reduces the width of crack. Increase in reinforced ratio and cover thickness decreases the crack width.

\section{Assessment of literature}

Most of the researchers dedicated their work in finding the influence of process parameters on mechanical properties of the rotomoulded products. They have extended their work by considering different thermoplastic powders and their combinations. Various attempts are made to observe the changes in the mechanical properties of the polymer when it is added to the additives and blowing agents. Normally the additives and blowing agents are added to increase any of the mechanical properties like impact strength, flexural strength, etc. whichever is significant to the application of the product. Extensive review of the literature clearly states that most of the researchers focus on the mechanical properties only. In order to increase the quality and reliability of the rotomoulded products, researchers handled different methods, processes and polymers. This ultimately increased some of the mechanical properties influencing the process parameters like temperature inside the mould, surface tension, vacuum and pressure, etc. Few attempts have also been made to look into the fracture aspects of the some polymers. The effect of process parameters on the mechanical properties and the product are summarized in table 1.

Table 1. Effect of process parameter on mechanical properties and rotomoulded products.

\begin{tabular}{|c|c|c|c|}
\hline Sl no. & Process parameters & Effect on products & Mechanical property \\
\hline 1 & $\begin{array}{l}\text { Low viscous material } \\
\text { (MFI } 25 \mathrm{~g} / 10 \mathrm{~min} \text { ) }\end{array}$ & $\begin{array}{l}\text { No bubbles and } \\
\text { no surface pores }\end{array}$ & Not applicable \\
\hline 2 & Overheating & $\begin{array}{l}\text { Reduces bubbles but } \\
\text { increases cycle time }\end{array}$ & $\begin{array}{l}\text { Reduces mechanical } \\
\text { strength }\end{array}$ \\
\hline 3 & $\begin{array}{l}\text { Two layer moulding } \\
\text { (eg-polyethylene+ Hollow } \\
\text { glass/ceramic micro spheres) }\end{array}$ & $\begin{array}{l}\text { Reduction in shrinkage } \\
\text { Dimensionally stable }\end{array}$ & Not applicable \\
\hline 4 & Addition of sintering enhancer & $\begin{array}{l}\text { Uniform part thickness and } \\
\text { reduction in cycle time }\end{array}$ & $\begin{array}{c}\text { Do not have adverse effect on } \\
\text { impact strength }\end{array}$ \\
\hline 5 & Faster cooling rate & Reduces residual stress & Increase the impact strength \\
\hline 6 & Temperature & $\begin{array}{l}\text { Product will not be denser } \\
\text { as temperature increases. }\end{array}$ & $\begin{array}{c}\text { Hardness increases at low } \\
\text { temperature }\end{array}$ \\
\hline 7 & $\begin{array}{l}\text { Increase in addition } \\
\text { of foaming agents }\end{array}$ & $\begin{array}{l}\text { Reduces the warpage } \\
\text { of the product }\end{array}$ & Increase impact strength \\
\hline 8 & Finer particles of powder & Not applicable & Reduces the impact strength \\
\hline 9 & Increase in density & Not applicable & Increases the impact strength \\
\hline 10 & $\begin{array}{l}\text { Addition of glass } \\
\text { micro spheres }\end{array}$ & Not applicable & Increase the impact strength \\
\hline 11 & $\begin{array}{l}\text { Addition of filler material } \\
\text { like talc and mica }\end{array}$ & Not applicable & $\begin{array}{c}\text { Improves hardness, tensile, } \\
\text { impact and heat deformation } \\
\text { resistance }\end{array}$ \\
\hline 12 & Presence of blowing agent & Not applicable & $\begin{array}{l}\text { Increase impact strength but } \\
\text { reduces tensile strength }\end{array}$ \\
\hline
\end{tabular}




\section{Conclusion}

In this work, extensive literature review of rotational moulding process using LLDPE has been carried out to summarize the present status of the characterization in order to maintain quality and reliability of products. It is inferred from the extensive literature that: even though different methods and processes are adopted in rotational moulding process, optimized parameter which in turn gives optimized product quality are not clearly defined. Rotational moulding products are used in some critical applications like oil tanks, chemical tanks and industrial equipments, etc. In view of criticality of the application of the rotational moulding products, it is necessary to know the fracture behaviour of the rotational moulding products which is not clearly investigated yet. As it is evident from the literature that the process variables play an important role in producing the effective and reliable products in rotational moulding, however, no attempt is made to address the correlation between the process parameters in rotational moulding process with fracture behaviour. Also, there is a need to investigate the influence of additives, foaming agents and blowing agents on the fracture behaviour of the rotational moulding products. Since, the real time applications demand the fracture characterization, a scope for the research arises to find the influence of these agents on the fracture toughness.

As it is stated earlier, the components fabricated from polymers especially polyethylene are more often prone to failure under impact loading and this tendency of failure is promoted by the presence of sharp flaws, especially at room temperatures. Thus, fracture behaviour of the polyethylene is greatly influenced by the mechanical properties, which in turn depends on process parameters. Further, the work can be extended to correlate the mechanical properties of polyethylene with its fracture behaviour.

\section{References}

Abbas Tcharkhtchi and Jacques Verdu 2004 Structure - processibility relationship during rotational moulding of plastics. J. Adv. Eng. Mater. 6: 983-992

Aiello M A and Ombres L 2000 Crack analysis of frp-reinforced concrete flexural members. J. Mech. Compos. Mater. 36: 645-654

Alesseandro Pegoretti, Elisa Bertoldi and Theonis Ricco 2005 Plane stress fracture toughness of ductile polymeric flims: Effect of strain rate on the essential work of fracture parameters. $11^{\text {th }}$ Int. Conf. on Fract. Turin, Italy, 20-25

Alongkorn Kanokboriboon and Harkin-Jones E 2005 Processibility and properties of a rotomolded nano composite. J. Rotation 6: 61-64

Antonio Greco and Alfonso Maffezzoli 2004 Powder-shape analysis and sintering behavior of high-density polyethylene powders for rotational molding. J. Appl. Polym. Sci. 92: 449-460

Archer E, Harkin Jones E, Kearns M P, Crawford R J and Fatnes A M 2002 An investigation of the rotational moulding of foamed metallocene polythenes. J. Rotation 13: 27-29

Bharat Indu Chaudhary, Elizabeth Takacs and John Vlachopoulos 2001 Processing enhancers for rotational molding of polyethylene. J. Polym. Eng. Sci. 41: 1731-1742

Carla F M, Mohammad A I and Prakash Vikas 2007 Dynamic Fracture of linear medium polyethylene under impact loading conditions. J. Mater. Sci. Eng. 465: 211-222

Crawford R J 1994 Causes and cures of problems during rotomoulding. J. Rotation 3: 10-14

Crawford R J 1996 Recent advances in the manufacture of plastic products by rotomoulding. J. Mater. Process. Technol. 56: 263-271

Crawford R J 2000 Residual stress in rotational moulded parts. J. Rotation 11: 20-24

Crawford R J 2003 Vision 2020 through 2002. J. Rotation 11: 16-19 
Francis M, Mirabella J R, Stanley P and Westphal P L 1988 Morphological explanation of the extraordinary fracture toughness of linear low density polyethylenes. J. Polym. Sci. 26: 1995-2005

Guobin L, Chul Park B and John Lefas A 2004 Rotational moulding of low-density lldpe foams. J. Polym. Eng. Sci. 38: 1997-2009

Laws R D 2004 An in-depth look at the influential factors of the dry-flow/bulk-density test used in the rotomoulding industry. J. Rotation 10: 12-14

Mark Kearns P and Neil Collan M 2000 The use of hollow microspheres in rotational moulding of plastic parts - part 2: Two layer moulding. J. Rotation 8: 20-24

Mark Kearns P, Warren Wallace, Michael Murphy, Cecil Armstrong and Crawford R J 2001 An introduction to the use of additional uv absorbers in the rotational moulding process. J. Rotation 5: 18-22

McNally G M, McCourt M K and Crawford R J 2002 A new method for observing density changes of plastics during rotational moulding. J. Rotation 14: 46-48

Olinek J, Anand C and Bellehumeur C T 2005 Experimental study on the flow and deposition of powder particles in rotational moulding. J. Polym. Eng. Sci. 45: 62-73

Oliveria M J and Cramez M C 2001 Rotational moulding of polyolefins: processing, morphology, and properties. J. Macromol. Sci. Part B Phys. 40: 457-471

Pick E L T and Eileen Harkin-Jones 2003a An Investigation in to relationship between the impact performance of rotationally moulded polyethylene products and their dynamic mechanical properties. $J$. Polym. Eng. Sci. 43: 905-918

Pick E L T and Harkin-Jones 2003b Understanding the impact behavior of rotomoulded linear low density polyethylene. J. Rotation 13: 26-30

Pick L, Harkin-Jones E, Kearns M P and Crawford R J 2003 A Comparison between the impact performance of rotationaly moulded linear low density polyethylene with metallocene polyethylene. $J$. Rotation 9: 21-25

Robert A, Orr J F and Crawford R J 2000 Influence of mica and talc fillers on the properties of rotational moulded lldpe. ANTEC Int. Conference on Processing. Orlando, Florida, 1399-1404

Shih-Jung Liu and Chja-Hsun Tsai 1999 An experimental study of foamed polyethylene in rotational moulding. J. Polym. Eng. Sci. 39: 1776-1786

Shih-Jung Liu 2000 Optimizing the impact strength of rotational moulded parts. J. Polym. Sci. Eng. 40: 473-480

Spence A G and Crawford R J 1996 The effect of processing variables on the formation and removal of bubbles in rotationally moulded products. J. Polym. Eng. Sci. 36: 993-1009

Tamas Barany, Tibor Czigany and Jozsef Karger-Kocsis 2003 Essential work of fracture concept in polymers. J. Period. Polytech. Ser. Mech. Eng. 47: 91-102

Tan S B, Hornsby P R, Mcfee M B, Kearns M P and McCourt M P 2011 Internal cooling in rotational moulding - a review. J. Polym. Eng. Sci. 51: 1683-1692

Throne J L and Sohn M S 1989 Structure-property considerations for rotationally molded polyethylenes. Adv. Polym. Tech. 9: 193-209

Tjong S C and Bao S P 2007 Fracture toughness of high density polyethylene/sebs-g-ma/montmorillonite nanocomposites. J. Compos. Sci. Technol. 67: 314-323

Van Hooijdonk J P F, Mark Kearns P, Armstrong C G and Crawford R J 2001 Effect of processing conditions on the properties of rotationally moulded polypropylene. J. Rotation 6: 28-30

Yan W, Lin R J, Bickerton S and Bhattacharyya D 2003 Rotational moulding of particulate reinforced polymeric shell structures. J. Rotation 10: 16-19 